\title{
Health systems science can learn from medicine's evidence revolution
}

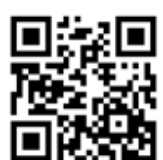

Can tuberculosis be cured? Yes. Can we eradicate polio? Definitely. So why are these diseases still out there, causing suffering and hastening death? Why do proven, effective interventions stop short of achieving their potential? Because weak health systems - the combination of actors, institutions, policies and resources that strive to improve population health - prevent well-intentioned policies from being translated into population benefits. ${ }^{[1]}$ The problem is that there is little useful evidence to help policy makers decide how to make their health systems stronger - or even to gauge what 'stronger' really means. ${ }^{[2]}$

Current understanding of the complex systems that govern health is so poor that we are unable to measure, monitor or manipulate them meaningfully. Centuries of experience have somehow managed to produce little actual evidence to guide future efforts. ${ }^{[1,2]}$ The reason is that while many countries have demonstrated noteworthy health systems successes - and, importantly, failures - systematic documentation of plans, implementation and outcomes is rare. As a result, lessons learned are all but lost. Without robust tailored tools such as the randomised controlled trial (RCT) to facilitate systematic investigation, the field of health reform and development is akin to what medicine was 50 years ago: an art based on expert opinion, rather than a science based on evidence. ${ }^{[3]}$

By contrast, it is almost inconceivable now to think of a time when clinical medicine had no formalised system of testing or comparing treatments, or of quantifying their likely effects. A time when drug companies could manufacture and market products with no requirement that they actually worked, and when new doctors were trained on the combined experience of their predecessors to repeat old habits with blind faith. ${ }^{[4]}$ In just a single generation - not more than 30 years - a thought-revolution has been fought and won. Medicine is no longer just about providing an authoritative opinion and some sympathy, and leaving nature to take its course..$^{[5]}$ There is a vast and expanding body of knowledge that means that doctors' recommendations have a basis in fact. There may be some way to go in refining the techniques, ${ }^{[6]}$ but it is fair to say that, for medicine, if not its practitioners, ${ }^{[7]}$ the scientific conversion is complete.

So what can health systems specialists learn from medicine? The list of useful parallels is fairly long. The revolution in medicine started with a simple idea: that every clinical decision should be considered a hypothesis to be tested. Health systems science could approach policy decisions the same way. Some key steps were pivotal in turning this idea into a movement. First, and most crucial, was the development of the RCT. The technique of randomisation minimises biases and enables investigators to isolate the treatment effect from confounders. Application of this method to common interventions yielded many surprises, and enabled doctors to discard widely used treatments that were shown not to work. ${ }^{[4]}$ There have been attempts to adapt the RCT to testing of development interventions, but so far with mixed success and much debate. ${ }^{[7]}$

The second key step in medicine's 'scientification' process was the broad acknowledgement that scientific investigation is an essential complement to clinical skills. ${ }^{[8]}$ A subsequent education upheaval in medical schools transformed both current and future doctors into competent users of scientific literature, and motivated investigators. ${ }^{[9]}$ On these last two steps, health systems science is far behind. The challenge is that systems are much more complicated than individual patients, with diagnoses and interventions that are far less well defined. What works in one country, region or facility may not work in another. Useful knowledge that could help policymakers' decision-making is scattered across several disciplines. No single cadre of workers, such as doctors, decides and administers the intervention (treatment) to a system (patient). Multiple actors with different backgrounds and competing priorities all influence health systems and service delivery in different ways. ${ }^{[10]}$ Because of this complex interplay of politics, people and priorities, experimental conditions are near-impossible to create, and findings from one health system context are difficult to translate to others.

Despite these challenges, there is much to be gained if health systems specialists embrace the conventions of science, as medicine has done. ${ }^{[10,1]}$ Sharing knowledge among actors and across disciplines, so that lessons can be learnt and built upon, is the first step. This is what science does best. Evidence-based medicine teaches that experiential knowledge is crucial for 'the conscientious, explicit, and judicious use of current best evidence in making decisions. ${ }^{[12]}$ And, here, health systems science can learn once again. Combining these two types of knowledge - evidence and experience - is the key that transforms art to science.

It is with this rationale that, this month, we are proud to announce the launch of a new journal, Strengthening Health Systems (SHS), which aims to tackle the science deficit in health and development and fill evidence gaps. International, peer reviewed and open access, as journals should be, SHS intends to capture all forms of health systems knowledge - whether from academics, policy makers,

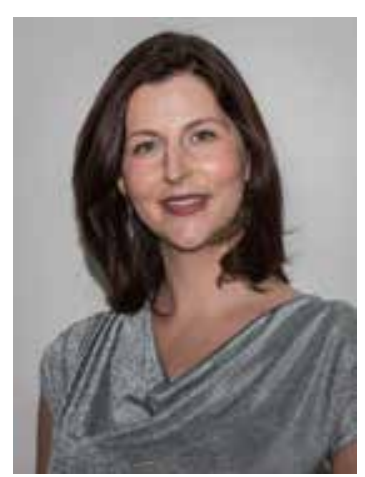
donors or implementers - and, by doing so, strengthen links between research and practice. In this field where opinions so often trump facts, medicine's enduring lesson is this: knowledge may come from many sources, but the scientific record is the foundation on which progress is built.

\section{Hannah Kikaya}

Editor, Strengthening Health Systems hannah.kikaya@hmpg.co.za

1. World Health Organization. World Health Report 2000. Health Systems: Improving Performance. Geneva: World Health Organization, 2000.

2. Alliance for Health Policy and Systems Research. Strengthening Health Systems: The Role and Promise of Policy and Systems Research. Geneva: World Health Organization, 2004.

of Policy and Systems Research. Geneva: World Health Organization, 2004.
Smith R, Rennie D. Evidence based medicine - an oral history. BMI 2014;348:g371. [http://dx.doi. Smith R, Rennie D. Ev
org/10.1136/bmj.g371]

4. Cochrane AL. Effectiveness and Efficiency: Random Reflections on Health Services. London: Nuffield Provincial Hospitals Trust, 1972

Simel DL, Rennie D. The Rational Clinical Examination: Evidence-based Clinical Diagnosis. American Medical Association, 2009.

Every-Palmer S, Howick J. How evidence-based medicine is failing due to biased trials and selective publication. J Eval Clin Pract 2014; E-pub: 12 May. [http://dx.doi.org/10.1111/jep.12147]

Smith R. Doctors are not scientists. BMJ 2004;328(7454):0.9. [http://dx.doi.org/10.1136 bmj.328.7454.0-h]

Pritchett L. RCTs in development: Lessons from the Hype Cycle. Center for Global Development blogs, November 2013. [http://www.cgdev.org/blog/rcts-development-lessons-hype-cycle] (accessed 8 June 2014).

9. Guyatt GH, Rennie D. Users' guides to the medical literature. JAMA 1993;270(17):2096-2097.

10. Kim IY, Farmer P, Porter ME. Redefining global health care delivery. Lancet 2013;382(9897):10601069. [http://dx.doi.org/10.1016/S0140-6736(13)61047-8]

11. Alliance for Health Policy and Systems Research. Health Research to Practice: Make it Happen - How Alliance for Health Policy and Systems Research. Health Research to Practice: Make it Happen - How
Decision-makers Can Use Policy and Systems Research to Strengthen Health Systems. Geneva: Global Forum for Health Research, 2005.

12. Sackett DL, Rosenberg WMC, Gray AM, et al. Evidence based medicine: What it is and what it isn't. BMJ 1996;312(7023):71-72. 